\title{
LANDSCAPE PATTERNS AND DISPERSAL SUCCESS: SIMULATED POPULATION DYNAMICS IN THE BROWN TREECREEPER
}

\author{
Caren B. Cooper, ${ }^{1,3}$ Jeffrey R. Walters, ${ }^{1}$ And Jeffery Priddy ${ }^{2}$ \\ ${ }^{1}$ Department of Biology, Virginia Polytechnic Institute and State University, Blacksburg, Virginia 24061 USA
}

${ }^{2}$ Duke Marine Laboratory, Beaufort, North Carolina 28516 USA

\begin{abstract}
We used a spatially explicit, individual-based simulation model to explain the possible role of patch isolation in causing observed declines of Brown Treecreepers (Climacteris picumnus) in northern New South Wales, Australia. Using aerial photographs and a geographic information system, we created a spatially realistic landscape in which territories were constrained to woodlands and the matrix composition mimicked the actual landscape in the study area. We compared observed population behavior to the outcome of simulations based on two dispersal movement rules and three dispersal mortality rules. Under the first movement rule, a dispersing bird's initial direction was selected at random (Random); under the second rule, a bird's initial direction was toward its nearest neighbor (Neighbor). The first mortality rule used a constant mortality rate for dispersing birds, whereas the second and third varied mortality rate dependent on habitat type traversed. In simulations using the Random movement rule, populations in contiguous habitat were relatively stable, whereas populations in fragmented habitat steadily declined due to low female recruitment, which is the same pattern observed in the real population. Populations in both contiguous and fragmented habitat increased under the Neighbor movement rule, suggesting that population dynamics may be sensitive to dispersal search patterns. Varying mortality rate with habitat type had a large effect on population behavior even though longdistance dispersal was infrequent. Thus, for this cooperative breeder, where territories become clumped due to a high rate of territorial budding, matrix habitats continue to influence overall population performance. In this system, conservation efforts must address the quality of the matrix habitats as well as the configuration of remaining habitat.
\end{abstract}

Key words: Australian woodlands; Brown Treecreeper; Climacteris picumnus; cooperative breeder; dispersal success; habitat fragmentation; individual-based spatially explicit model; isolation effects; landscape patterns; simulated population dynamics.

\section{INTRODUCTION}

Habitat fragmentation resulting from land-use changes can affect bird populations in several ways, including altering birth, death, and dispersal rates. For the purposes of this paper, we use habitat fragmentation as a unifying term, encompassing many changes in the landscape, specifically changes in the amount of native habitat, the amount of new matrix habitat, the amount of edge between native and new habitats, and the distances between remnant patches of native habitat. Each of these landscape changes can potentially affect animal populations, but the extent of empirical and experimental evidence demonstrating each effect varies. Edge effects are well documented in some forest systems and result in decreased reproduction or survival of birds near the edges of patches. For example, rates of cowbird parasitism and nest predation on numerous species in North America are elevated near edges (Robinson et al. 1995). Edge effects are influenced by the

Manuscript received 25 July 2001; revised 15 October 2001; accepted 2 March 2002.

${ }^{3}$ Present address: 159 Sapsucker Woods Road, Cornell Lab of Ornithology, Ithaca, New York 14850 USA.

E-mail: cbc25@cornell.edu composition of the surrounding landscape as well as by patch size (Donovan et al. 1997). Isolation effects result in decreased dispersal success because individuals have difficulty moving between habitat fragments. There is much theoretical support for the existence of isolation effects, but few empirical studies (Harrison and Bruna 1999).

How fragmentation patterns affect the vital rates of a population is the subject of continuing research, but the development of a unified theory has been hindered by theoretical (Caughley 1994, Walters 1998) and logistical obstacles (Harrison and Bruna 1999). One major obstacle is that many effects occur at large scales, the exact extent of which is unknown, making experimentation and replication difficult. There have been only a few large-scale forest studies that have temporally and spatially replicated fragments, e.g., the $\mathrm{Bi}-$ ological Dynamics of Forest Fragments experiment in the Brazilian Amazon (Laurance and Bierregaard 1997) and work in boreal mixedwood forest in Canada (Schmiegelow et al. 1997). Manipulative experiments are usually limited to nonforested landscapes, such as micro-landscapes, experimental model systems, or fields (Wiens and Milne 1989, Wiens et al. 1993, Dooley and Bowers 1996, 1998, Gilbert et al. 1998). One 
approach has been to approximate a true experiment by selecting existing landscapes containing natural variation in fragmentation patterns as replicates (e.g., Trzcinski et al. 1999, Villard et al. 1999). Drawbacks to this approach include the frequent necessity to define fairly small landscapes in order to increase sample size (e.g., McGarigal and McComb 1995) and the inability to collect detailed demographic data across replicates. An alternative approach has been to use spatially explicit models (e.g., McKelvey et al. 1993, Fahrig 1997, 1998).

Brown Treecreepers (Climacteris picumnus) are a cooperatively breeding passerine and are declining in our New South Wales study area because the isolation of woodland fragments disrupts dispersal, resulting in low recruitment (Cooper and Walters 2002a). As a result, Brown Treecreeper distribution within woodland fragments is affected by the amount and spatial configuration of remaining woodland in the surrounding landscape (Cooper and Walters 2002b). The most commonly advocated management action to counter isolation of habitat patches (i.e., fragments) is corridor development. The implicit assumptions for this action are that isolation arises from a lack of physical connectivity and that corridors can mitigate isolation by reestablishing connectivity. However, this reasoning has been criticized because it is movement, not necessarily a physical connection, that is required to mitigate isolation effects (Simberloff et al. 1992, With 1997). Furthermore, dispersal could be disrupted through a variety of mechanisms indirectly related to the larger gaps between habitat patches in fragmented landscapes, such as increased dispersion of patches or the presence of inhospitable or low-quality habitat in gaps. Therefore, knowing that fragmentation is causing groups to be isolated is not sufficient information to make correct management decisions. Knowledge of the mechanisms underlying isolation effects is necessary. For example, if the matrix is a barrier to movement, then corridors of suitable habitat could be a viable management option. However, if it is the dispersion of patches rather than matrix composition that influences dispersal success, then retaining or creating an aggregated distribution of patches is appropriate.

Here we use a simulation model to address the following questions. First, how might the dispersion of territories, which is greatly influenced by the degree of aggregation of habitat patches, affect the dynamics of Brown Treecreeper populations? To address this question, we measure the effect of different territory distributions within and among remnant habitat patches on population performance and make inferences regarding the role of patch configuration on population dynamics. Second, can matrix composition (i.e., the interspersed patterns of various nonwoodland habitats in the landscape) account for the pattern of Brown Treecreeper declines? We employ an individual-based, spatially explicit simulation model to link individual dis- persal behavior and life-history variation to populationlevel outcomes. Such a model enables one to predict the properties of a population based on the behavioral responses of individuals that comprise the population, and here we examine the impact of dispersal behavior in particular. Letcher et al. (1998) created an individual-based, spatially explicit model of the population dynamics of the cooperatively breeding Red-cockaded Woodpecker (Picoides borealis). After adjusting the Letcher et al. (1998) model to match Brown Treecreeper life history, we simulate their population dynamics in a landscape developed with GIS software. Although similar models have been used to explore fragmentation effects (e.g., Doak et al. 1992, McKelvey et al. 1993, Liu et al. 1995), very few have addressed dispersal behavior and dispersal mortality, and even fewer have used real landscapes.

\section{Methods \\ Field study}

Study area.-The study site consists of Eucalyptus woodland patches within a $1500-\mathrm{km}^{2}$ region surrounding the town of Armidale, in the New England Tablelands of northeastern New South Wales, Australia $\left(30^{\circ} 27^{\prime} \mathrm{S}, 151^{\circ} 13^{\prime} \mathrm{E}\right.$; Fig. 1). The study area straddles the Great Dividing Range, with an elevation of 730$1300 \mathrm{~m}$, and is described in detail elsewhere (Cooper et al., in press).

Temperate Eucalyptus woodland communities are among the most poorly conserved ecosystems in Australia, with $\sim 70-95 \%$ of various woodland types having been replaced by agriculture and pasture (Yates and Hobbs 1996). In the landscape of the New England Tablelands, there is a gradient of tree densities ranging from completely cleared land to forests. With the aid of aerial photographs $(1992,1994)$ and topographic maps (each 1:25000), we used a geographic information system (ArcInfo 1999, version 7.2, Redlands, California, USA) to digitize cover types within the study area. Barret et al. (1994) and Barrett (1995) found that the Brown Treecreeper occurred in woodland patches as small as 9 ha. For the purposes of this study, we used a map of woodland and forest patches $>10$ ha (Fig. 1). We categorized the landscape cover types by tree densities and slope (Fig. 1). Brown Treecreepers do not breed in steep woodlands and forested gorges (Keast 1957, Noske 1982a, b).

Patch connectivity.-We distinguished fragmented habitat from contiguous habitat based on patch connectivity rather than patch size, because earlier studies showed that Brown Treecreepers are isolation sensitive rather than area sensitive (Cooper et al., in press). We used ArcView (ArcView 1992-1999, version 3.2, Redlands, California, USA) to compute connected patch size, a measure of patch connectivity, for each patch. Connected patch size was measured as the total area of the set of patches with $<200$-m gaps between them 


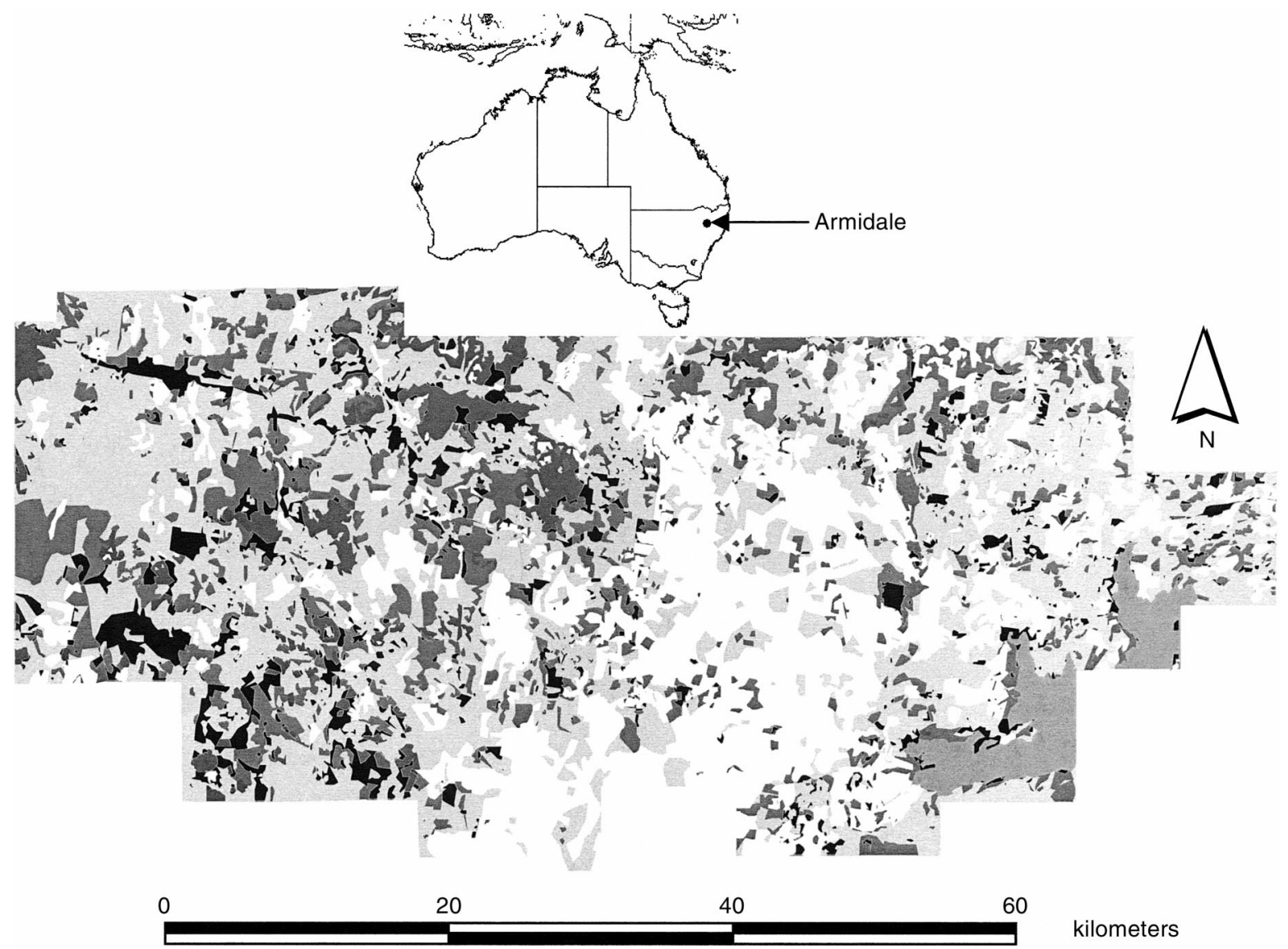

FIG. 1. Vegetation cover types in the study area, surrounding Armidale, New South Wales, Australia. This map was created in ArcInfo by referring to aerial photographs (copied with permission from NSW Center for Land Management, 1992, 1994) and topographic maps (NSW Mapping Service). We categorized habitat types in the landscape by the following tree densities: 0 trees/ha (cleared land, habitat value $=42) ; 1-10$ trees/ha $($ sparse trees, habitat value $=85) ; 10-50$ trees/ha (scattered trees, habitat value $=170$ ); and $>50$ trees/ha (woodlands, habitat value $=255$ ). Other areas with $>50$ trees/ha in steep terrain are classified as steep woods (habitat value $=212$ ), and some as forested gorges (habitat value $=127$ ). Cleared land included urban areas, lakes, and surface mines. Habitat types are shown in gray scale with white representing cleared land and each darker shade representing higher tree densities. The relative (average) habitat value is used to determine seasonal mortality rate based on functions in Fig. 3. Areas off the map edge had habitat value $=0$.

that included the focal patch. Although larger gaps may be perceived as "connected" by Brown Treecreepers, $200 \mathrm{~m}$ was the minimum distance between patches among which dispersal events were observed (Cooper and Walters 2002a). A totally isolated patch had a connected size equal to its individual patch size, whereas patches connected to several others had connected patch sizes much greater than their individual patch size. We measured connected patch sizes in our landscape and all were either $>2000$ ha or $<600$ ha. Therefore we were able to classify patches into two categories, those within contiguous (connected) woodland landscapes (within a connected patch of $>2000$ ha) and those within highly fragmented (unconnected) woodland landscapes (connected patch size $<600$ ha), as in Cooper and Walters (2002a) and Cooper et al. (in press).

Brown Treecreeper demographics.-We used data from the population of Brown Treecreepers inhabiting the study area to estimate many of the parameters of the model. Research on this population began in 1992 (Walters et al. 1999), with some additional data collection in 1995 (J. Walters, unpublished data), and continued from 1996 to 1998 (Cooper et al., in press). Over 50 groups were monitored, and $\sim 85 \%$ of adults and $84 \%$ of offspring were individually color-banded. Further details of population monitoring can be found in Cooper et al. (in press) and Cooper (2000). In the study area, Brown Treecreeper family groups defended territories averaging 4.5 ha and ranging from 1.1 to 10.7 ha (Cooper et al., in press).

The life history of the Brown Treecreeper is best modeled based on status classes of individuals with annual probabilities of transition between status classes. Female fledglings that survive usually disperse, and only rarely remain as helpers. Dispersers eventu- 
ally find a breeding vacancy or die. Male fledglings that survive rarely disperse; instead, they remain as helpers on their natal territory. Males may eventually obtain a breeding vacancy by either inheriting their natal territory or budding (Noske 1982a, Walters et al. 1999, Doerr and Doerr 2001). Generally, a breeder retains its status until death. Many males that become breeders through budding continue to help at their natal territory as well (Noske 1982a, Walters et al. 1999, Doerr and Doerr 2001). It is unknown how this affects group reproductive success, and this trait was not included in the model.

Previous research compared the demography of groups in contiguous (connected) and fragmented (unconnected) woodland landscapes as defined in this study (Walters et al. 1999; Cooper et al., in press). There was no difference in the average number of offspring produced per breeding group or in adult female mortality rates between fragmented and contiguous habitat. Yet, the number of female breeders in patches in fragmented habitat decreased over time because of low female recruitment from within and between patches. Also, the maximum female dispersal distance was lower in fragmented habitat. Finally, there were no solitary males in contiguous habitat because breeding vacancies were filled immediately, whereas many males remained solitary in fragmented habitat, failing to find a mate for long periods (except through experimental manipulation; Cooper and Walters 2002a).

\section{Modeling}

Model structure.-The model was developed to simulate the population dynamics of Red-cockaded Woodpeckers and is described in detail in Letcher et al. (1998). The model is an individual-based simulation because it tracks the life of each simulated bird as it interacts with other simulated birds and responds to the landscape. Reproduction and mortality are based on age- and status-dependent relationships and specified transition probabilities (Fig. 2; see Brown Treecreeper demographics). During each seasonal time step (3 mo), an individual can be either a fledgling, disperser, breeder, or (for males only), a helper or solitary, depending on its age and whether it has found a breeding site (territory). Transitions between status classes depend on local availability of breeding vacancies and on the competitive ability of individual birds and thus are emergent from the simulation. Male territory competition is based on two rules: the closest male wins and if there is a tie, the older bird wins. Helpers always win over dispersing males. Competition for female vacancies follows the same rules, except that a female does not fill a vacancy that contained her father or son.

The original model was modified in several ways for application to Brown Treecreepers. First, the landscape was interfaced with a GIS map so that the initial territory distribution could be constrained by the distribution of woodland habitat. In this Brown Treecreeper model, territories are circles with fixed $x$ - $y$ coordinates assigned randomly to woodland habitat prior to the beginning of each run. The size of each territory depends on the proximity to surrounding territories with a preselected maximum of $\sim 10$ ha (175 m radius) and a minimum of $\sim 5$ ha ( $125 \mathrm{~m}$ radius). The model also was modified so that new territories could form through budding at a preselected rate (C. Cooper, unpublished data). The budding process selects an occupied territory to bud, the potential bud is subjected to a habitat criteria (it must fall within woodlands), and then the oldest helper obtains the new budding territory with the status of solitary male. Many emergent and stochastic factors may result in a lower budding rate than specified.

The initial model had only one dispersal movement rule ("Random"), by which a random direction was selected for each dispersing bird, who continued in that direction until dying or successfully completing dispersal (i.e., becoming a breeder on a territory). For this paper, a second movement rule was added, by which dispersal begins with a bird moving in the direction of the closest neighboring territory and then continuing in that direction until death or successful dispersal. This movement rule, "Neighbor," increases the searching efficiency of dispersers, thus allowing any effects of fragmentation to arise primarily through the distance between groups.

Finally, the initial model had one dispersal mortality rate for male dispersers and one mortality rate for female dispersers. For this paper, two more mortality rates for all dispersers were added to the model. During each time step, each dispersing bird has a search range (1 km radius), within which it can compete for territory vacancies. Therefore, each dispersing bird does not exist at one point in the landscape every 3 mo, but within a search range that progresses in a selected direction, creating a $2 \mathrm{~km}$ wide dispersal path. Using the GIS map of habitat types within the study area (Fig. 1), the model computed the average habitat value in each bird's dispersal search range for each season. We made dispersal mortality dependent on landscape composition by multiplying the baseline seasonal mortality rate by this value, and simulated different levels of sensitivity to landscape composition by varying the relative values of habitat types. Although the actual habitat values were arbitrary, they were designed to alter sensitivity to landscape composition according to the degree to which habitat value increased with the density of trees. We followed this rule because of evidence that Brown Treecreepers are reluctant to cross open land (Cooper 2000).

Under the "Constant rule," the mortality rate was equal in all habitat types. For the other two rules, seasonal mortality rates were related to habitat type by functions that we selected. Both functions had a flat section (multiplier 1) that represented the approximate habitat quality present where the original baseline mor- 

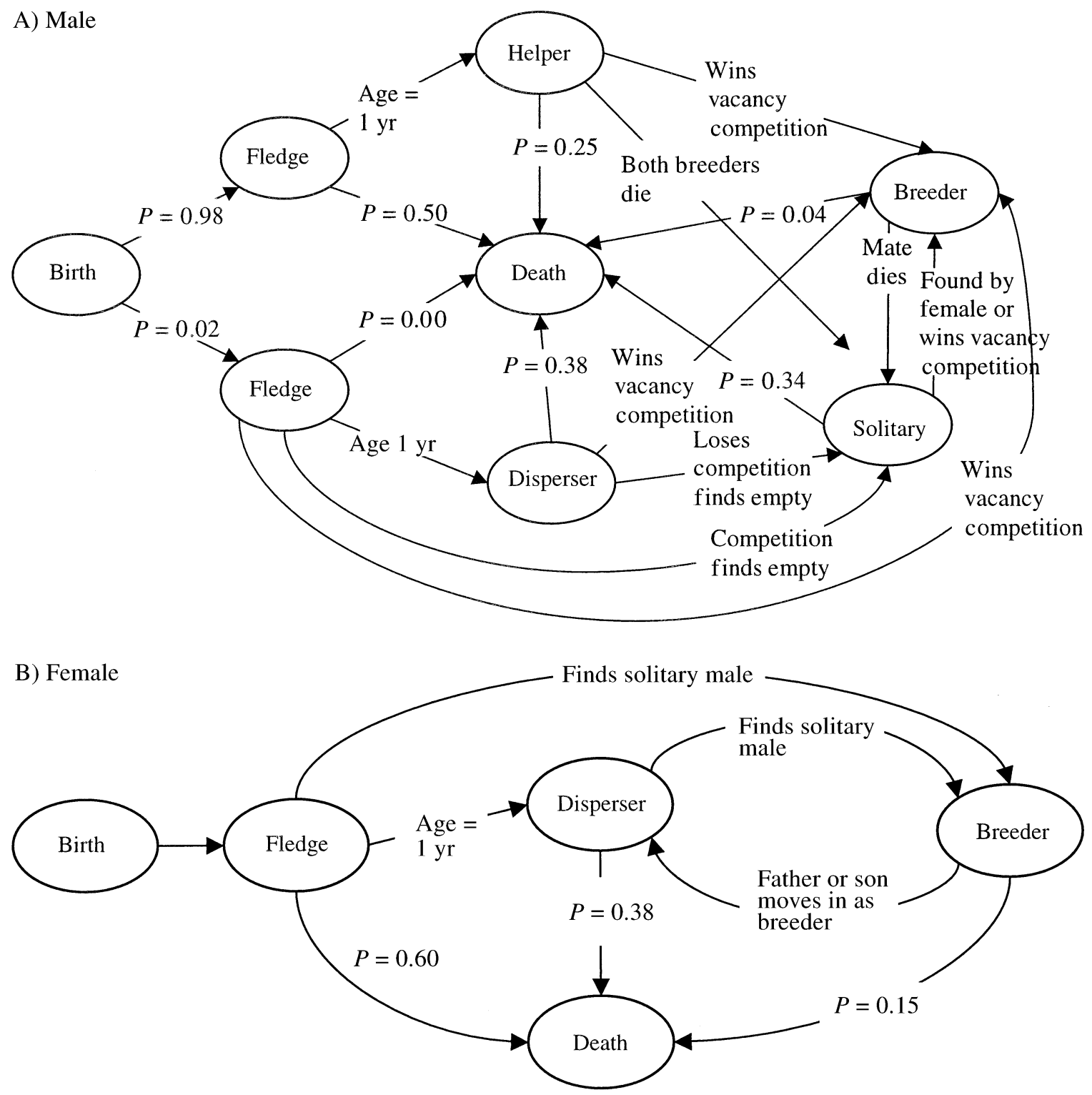

FIG. 2. Model flowchart with annual transition probabilities for (A) male and (B) female Brown Treecreepers. Some transition probabilities were estimated from Brown Treecreeper data (Cooper 2000; Cooper et al., in press) and Red-cockaded Woodpecker data (Letcher et al. 1998) (see Table 1). Other transitions do not occur at a specified rate, but emerge from the model based on local interactions and behavioral rules. For example, the probability that a helper will become a breeder depends on the number of breeding vacancies within $1 \mathrm{~km}$ of its territory and on the age of other males competing for that vacancy (oldest male wins). Other transitions were constant during some runs and variable during others. For example, the probability of a dispersing bird dying was variable during Cubic7 and Step20 runs (see Fig. 3).

tality estimates were made (Fig. 3; relative habitat quality 150-200). The "Cubic7" function simulated a mild effect of landscape matrix on dispersal mortality by creating a slight decrease in mortality for extremely good habitat (Fig. 3, 200-250), and a fairly rapid increase in mortality as habitat got worse, ending with a maximum multiplier of $\sim 7$ for the lowest habitat quality (Fig. 3). The "Step20" function simulated a more severe matrix effect by imposing a mortality multiplier of 20 for all habitat of less than optimal quality (i.e., relative habitat quality $<150$; Fig. 3). Seasonal mortality rates were related to annual mortality rates by the following equation: seasonal mortality rate $=1-$ $\left[(1-\text { annual mortality rate })^{1 / 4}\right]$.

We used parameter estimates from Red-cockaded Woodpeckers, Picoides borealis (see Letcher et al. 1998) as a substitute for those that we could not estimate for Brown Treecreepers. Red-cockaded Woodpeckers and Brown Treecreepers have similar ecology and life histories (e.g., they are both cooperative breed- 

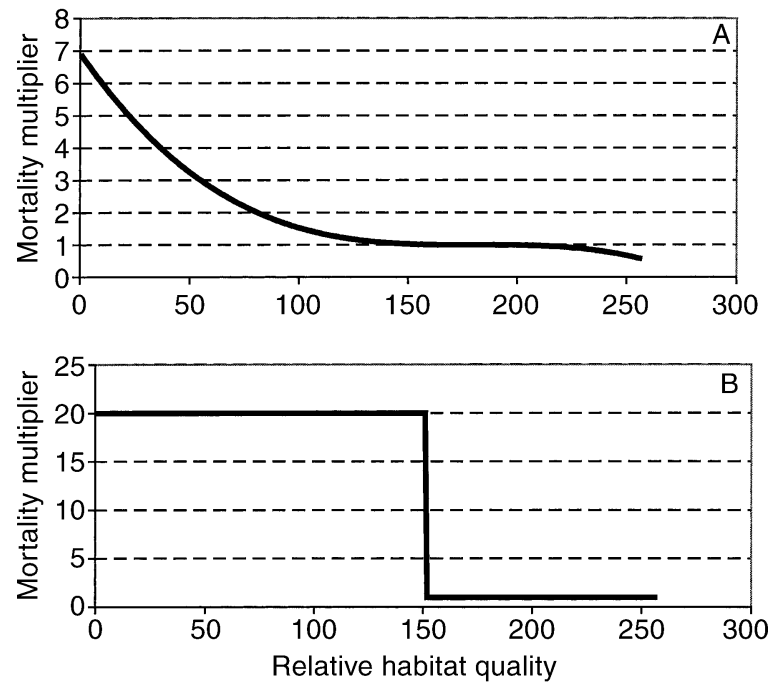

FIG. 3. Functions establishing the relationship between the mortality multiplier and the relative habitat quality in a bird's dispersal search radius (see Fig. 1). (A) Cubic7 follows a cubic function to a maximum multiplier of 7 . Therefore, when the habitat quality within a bird's seasonal search radius is 0 , the bird will experience a mortality rate seven times higher than baseline (Table 1). (B) Step20 assigns a multiplier of 20 to all dispersers in an average habitat quality below 150 .

ers, insectivorous, and cavity nesters). The initial age distribution was based on that of woodpeckers for similar reasons. Table 1 summarizes the input parameters. All input parameters were the same for birds in fragmented and contiguous habitat because, as previously mentioned, reproduction and mortality rates did not differ between these populations in the field (Cooper et al., in press). Demographic stochasticity was included in the model in order to create a variance in nest failure, fledging success, and mortality. Birds died and were removed from the simulation if a deviate from a random uniform distribution $(0: 1)$ was less than the probability of mortality (Table 1 ). Similarly, a nest failed if a deviate from a random uniform distribution was less than the probability of nest failure (0.29).

Variance in fledging success, the number of fledglings from a successful nest, comes from a regression model created from field data (Table 1). We used the mean number of fledglings based on the regression intercept (Table 1) and the group size as the mean in a random distribution with a standard deviation estimated from actual data (1.02) to generate the realized number fledged. If the number of fledglings generated from the normal distribution was less than one, contradicting the success of the nest, then the number fledged was set at one.

Model runs.-At the start of each model run, territories were placed randomly throughout woodlands until they covered $\sim 10 \%$ of woodland area, creating a pattern similar to that observed in the field. Territory distribution changed over the duration of each run as territories went extinct (after being unoccupied for $>5$ yr) and as territories formed by budding from existing territories. The original model was not sensitive to initial conditions (Letcher et al. 1998). Therefore, we allowed all runs to begin with the same initial conditions, by which $90 \%$ of all territories were assigned a breeding male and female, $50 \%$ of breeding groups were assigned a helper, and $10 \%$ of territories were assigned solitary males.

We extracted several output variables from the simulation for comparison of simulated contiguous and fragmented populations with field observations. Specifically, we examined population size (measured as number of breeding pairs) at the end of each run, the maximum female dispersal distances, and the percentage of long-distance $(>3.5 \mathrm{~km})$ dispersal events. Also, we compared the proportion of solitary males in contiguous vs. fragmented populations that obtained a mate before dying.

We present results from seven sets of model runs, using 20 replicate runs for each model set, in order to explore model behavior and how territory spatial arrangement and matrix composition affect population dynamics in contiguous and fragmented habitat. The duration of all runs was 100 yr. Because territory clumping gradually departed from initial conditions and became much more aggregated than that observed in the field by $45 \mathrm{yr}$, we examined output from the first $40 \mathrm{yr}$ of each run. Modeling short time periods often is preferable in order to minimize error propagation (Beissinger and Westphal 1998).

In the first set of runs, we evaluated the sensitivity of overall population growth rate $(\lambda)$ to the input parameters to determine which parts of the model had the largest effects on population behavior under nominal conditions. We varied 19 model parameters (see Table 1 ) by $\pm 25 \%$ independently in separate runs, and ran 20 replicate simulations of each condition. The sensitivity of the model to changes in each parameter was calculated as $\left(y_{+}-y_{-}\right) /\left(0.5 y_{0}\right)$, where $y_{+}$and $y_{-}$are the output values $(\lambda)$ with parameters adjusted $\pm 25 \%$, respectively, and $y_{0}$ is the mean output value using unadjusted parameters. Mean output values were computed as the average result of 20 baseline runs with the "Random" movement rule and the "Constant" mortality rule. Sensitivities $>1$ or $<-1$ indicate that changes in the parameter had a greater than proportional effect on the outcome of the model.

The remaining six sets of runs comprised a factorial design with the two movement rules and three mortality rules: Random, Constant; Random, Cubic7; Random, Step20; Neighbor, Constant; Neighbor, Cubic7; and Neighbor, Step20. All output values were computed as the mean $( \pm 1 \mathrm{SD})$ of 20 replicate runs. We used a three-factor ANOVA, with location (contiguous and fragmented), movement rule (Random and Neighbor), and matrix effect (Constant, Cubic 7, and Step 20) as factors to examine differences among sets of runs. 
TABLE 1. Model parameters from the original Red-cockaded Woodpecker (RCW) model (Letcher et al. 1998) and the Brown Treecreeper (BT) model, and sensitivity of the overall population growth rate $(\lambda)$ to these parameters.

\begin{tabular}{|c|c|c|c|}
\hline Parameter & $\mathrm{RCW}$ & BT & $\begin{array}{l}\text { Sensitivi- } \\
\text { ty to } \lambda\end{array}$ \\
\hline \multicolumn{4}{|l|}{ Annual mortality } \\
\hline Male fledglings $\dagger$ & 0.50 & $\ddagger$ & -0.088 \\
\hline Male dispersers $\dagger$ & 0.38 & $\ddagger$ & 0.005 \\
\hline Male helpers $\dagger$ & 0.20 & 0.25 & -0.035 \\
\hline Male solitary birds $\dagger$ & 0.34 & $\ddagger$ & -0.082 \\
\hline Male breeders $\dagger$ & 0.23 & 0.04 & -0.012 \\
\hline Female fledglings $\dagger$ & 0.58 & 0.60 & -0.205 \\
\hline Female dispersers $\dagger$ & 0.38 & $\ddagger$ & -0.015 \\
\hline Female breeders $\dagger$ & 0.29 & 0.15 & -0.137 \\
\hline \multicolumn{4}{|l|}{ Dispersal } \\
\hline Prop. of male fledglings dispersing $\dagger$ & 0.19 & 0.02 & 0.015 \\
\hline Male fledgling speed $(\mathrm{km} / \mathrm{yr}) \dagger$ & 5.1 & $\ddagger$ & -0.002 \\
\hline Male disperser speed $(\mathrm{km} / \mathrm{yr}) \dagger$ & 2.3 & $\ddagger$ & 0.013 \\
\hline Female fledgling speed $(\mathrm{km} / \mathrm{yr}) \dagger$ & 4.8 & $\ddagger$ & -0.076 \\
\hline Female disperser speed $(\mathrm{km} / \mathrm{yr}) \dagger$ & 4.8 & \# & -0.005 \\
\hline Male dispersing search range $(\mathrm{km}) \dagger$ & 3 & 1 & -0.005 \\
\hline Replace breeder search range $(\mathrm{km}) \dagger$ & 3 & 1 & 0.014 \\
\hline Female dispersing search range $(\mathrm{km}) \dagger$ & 3 & 1 & 0.144 \\
\hline Chance of leaving in season $2(\%)$ & 33 & $\ddagger$ & \\
\hline Chance of leaving in season $3(\%)$ & 33 & $\ddagger$ & \\
\hline Chance of leaving in season $4(\%)$ & 33 & $\$$ & \\
\hline Chance of solitary male leaving (\%) & 0 & $\ddagger$ & \\
\hline Male takes empty terr. when no vacancy (\%) & 100 & $\ddagger$ & \\
\hline Dispersal direction & random & 末, neighbor & \\
\hline \multicolumn{4}{|l|}{ Fecundity } \\
\hline Nest failure model type & negative exponential & $\ddagger$ & \\
\hline Nest failure model intercept $\dagger$ & 2.3404 & 0.9163 & 0.071 \\
\hline Nest failure model male's effect & -2.4295 & 0 & \\
\hline Nest failure model female's effect & -1.1527 & 0 & \\
\hline Nest failure model helper effect & -1.1012 & 0 & \\
\hline Mean fledgling model type & negative exponential & $\ddagger$ & \\
\hline Mean fledgling model intercept $\dagger$ & 2.06570 & 1.70575 & 0.197 \\
\hline Mean fledgling male effect & -1.18634 & 0 & \\
\hline Mean fledgling female effect & -1.03431 & 0 & \\
\hline Mean fledgling helper effect & 0.28401 & 0.31901 & \\
\hline Renesting probability & 0.319 & 0 & \\
\hline \multicolumn{4}{|l|}{ Initial conditions } \\
\hline Territory coverage $(\%)$ & NA & 10 & \\
\hline Male occupancy $(\%)$ & 100 & $\ddagger$ & \\
\hline Solitary males $(\%)$ & 10 & $\ddagger$ & \\
\hline Territories with helpers (\%) & 50 & $\ddagger$ & \\
\hline Breeding pair occupancy (\%) & 90 & $\$$ & \\
\hline Age distribution & $1900 \mathrm{RCW}$ data & $\ddagger$ & \\
\hline \multicolumn{4}{|l|}{ Landscape } \\
\hline Scale (pixels/km) & 20 & 40 & \\
\hline Size $(\mathrm{km} \times \mathrm{km})$ & $32 \times 24$ & $89.1 \times 41.55$ & \\
\hline Budding rate $(\%) \dagger$ & 1 & 7.5 & 0.075 \\
\hline \multicolumn{4}{|l|}{ Miscellaneous } \\
\hline Maximum bird age (yr) & 15 & $\ddagger$ & \\
\hline Disuse time before territory removal $(\mathrm{yr})$ & 5 & $\ddagger$ & \\
\hline Emigration test forward angle $\left({ }^{\circ}\right)$ & 180 & $\ddagger$ & \\
\hline Emigration test forward distance $(\mathrm{km})$ & 100 & $\ddagger$ & \\
\hline Radial search resolution & $10 / 3 \mathrm{~km}$ & $10 / 1 \mathrm{~km}$ & \\
\hline Angular bird search resolution & $21 / 360^{\circ}$ & + & \\
\hline
\end{tabular}

Note: When possible, treecreeper parameters were estimated from empirical data (Cooper 2000; Cooper et al., in press).

$\dagger$ Parameters that were included in the sensitivity analysis.

$\$$ Cases in which woodpecker parameters were used in the treecreeper model. 

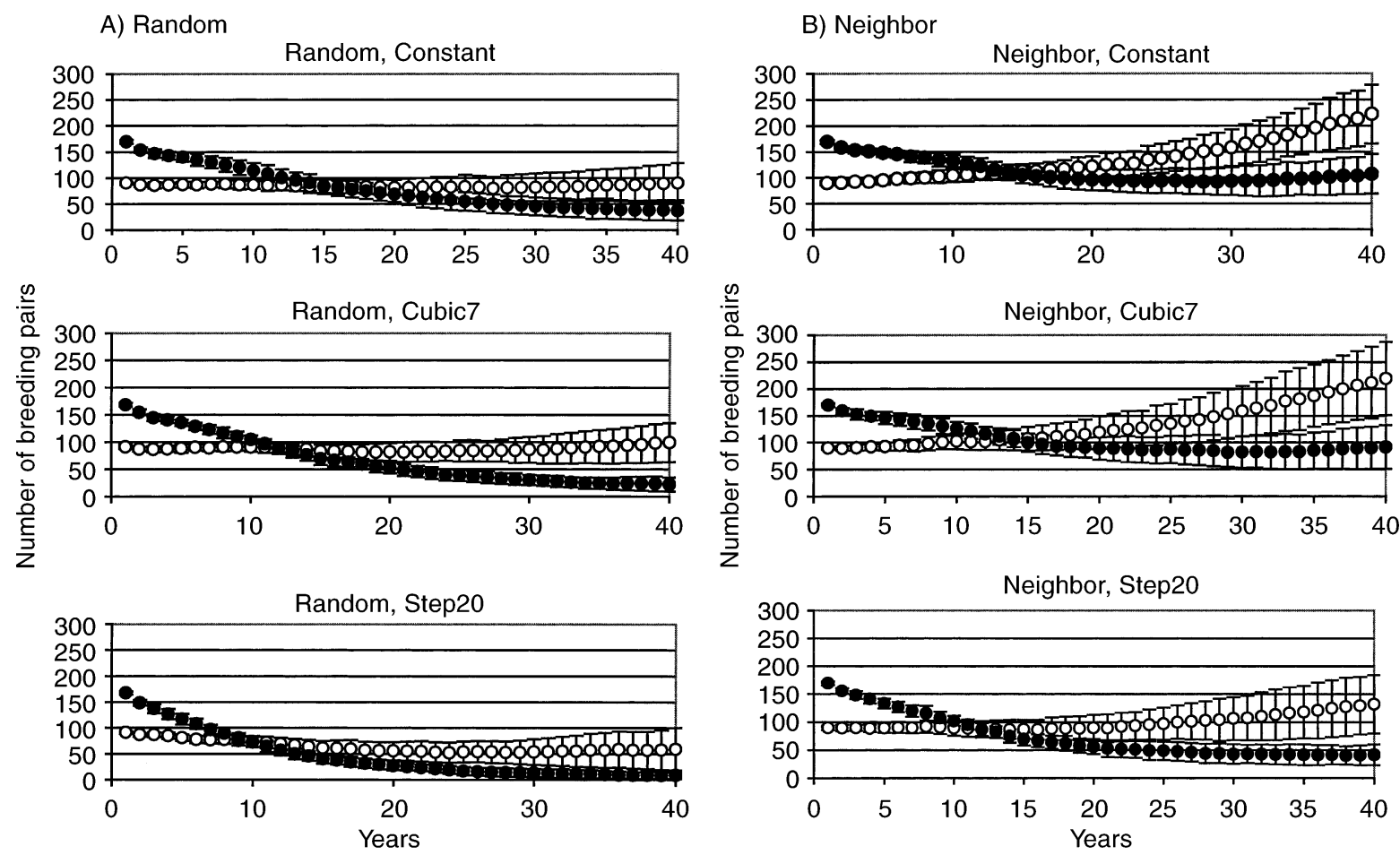

FIG. 4. Number of breeding pairs (mean \pm 1 SD of 20 runs) over $40 \mathrm{yr}$ in fragmented (closed circles) and contiguous (open circles) habitat for each set of runs. Random and Neighbor refer to dispersal movement rules and Constant, Cubic7, and Step20 refer to dispersal mortality rules (see Methods: Modeling, Model structure).

\section{RESULTS}

Proportional sensitivity analysis.-The performance of the model was robust to changes in parameter values. The largest proportional sensitivities of overall population growth rate $(\lambda)$ were approximately \pm 0.2 (Table 1). Female and male fledgling mortality, female breeder mortality, and solitary male mortality had the largest (negative) sensitivities. (Negative sensitivity means that an increase in the parameter results in a decrease in $\lambda$.)

Mean population size.-Initial group size and group productivity did not differ between contiguous and fragmented habitat because the same model rules were applied to all territories, regardless of location. Nevertheless, populations in contiguous habitat remained relatively stable or increased relative to populations in fragmented habitat within each run (Fig. 4). Populations in fragmented and contiguous habitat always did better under the Neighbor rule than the Random movement rule for each dispersal mortality rule, and worse under the Step20 mortality rule than the other mortality rules.

Mean population size at Y40.-Even though the number of breeding pairs in fragmented habitat always started out higher than the number in contiguous habitat due to the relative amount of habitat, the fragmented population always became smaller than the contiguous population by the end of runs (Table 2). Population size after $40 \mathrm{yr}$ was lower in fragmented than in contiguous habitat, especially with the Neighbor movement rule and matrix effects on mortality (Table 2). Population size after $40 \mathrm{yr}$ was lower with the Random movement rule, and lowest with the Step20 disperser mortality rate (Table 2 ).

Movement between fragmented and contiguous habitat.-We defined contiguous and fragmented habitat based on connectivity. However, a small percentage of birds (3-14\%) successfully dispersed between contiguous and fragmented habitat during each run. When we restricted further analyses of dispersal events (i.e., female dispersal movements and long-distance movements) to only those dispersing birds that did not cross between contiguous and fragmented habitat, the results did not differ. Therefore, we report results using all successful dispersal events in the following analyses.

Female dispersal distances. - The average maximum dispersal distance of females did not differ between fragmented and contiguous habitat, yet was greater with the Neighbor movement rule and with Constant mortality rates (Table 2). Only runs with the most severe matrix effect (Step20) produced maximum dispersal distances as short as those observed in the field (Table 2).

Long-distance dispersal events.-Short-distance dispersal events were always more frequent than longdistance dispersal events. The proportion of long-dis- 
TABLe 2. Mean (and $1 \mathrm{SD}$ ) from 20 replicate runs for several model output parameters in fragmented and contiguous habitat, under Random and Neighbor movement rules, and under Constant, Cubic7 (mild matrix effect), and Step20 (severe matrix effect) mortality rates compared to real data.

\begin{tabular}{|c|c|c|c|c|c|c|c|}
\hline \multirow{2}{*}{$\begin{array}{l}\text { Parameter and } \\
\text { habitat status }\end{array}$} & \multicolumn{3}{|c|}{ Neighbor } & \multicolumn{3}{|c|}{ Random } & \multirow{2}{*}{$\begin{array}{l}\text { Real } \\
\text { data }\end{array}$} \\
\hline & Constant & Cubic7 & Step20 & Constant & Cubic7 & Step20 & \\
\hline \multicolumn{8}{|c|}{ Mean population size at Y40 (no. groups) } \\
\hline Contiguous & $222(56)$ & $219(68)$ & $132(52)$ & $90(37)$ & $99(22)$ & $59(41)$ & \\
\hline Fragmented & $107(38)$ & $91(41)$ & $42(18)$ & 37 (19) & $22(13)$ & $8(7)$ & \\
\hline \multicolumn{8}{|c|}{ Mean maximum distance $(\mathrm{km})$} \\
\hline Contiguous & $29(6)$ & $27(3)$ & $8(1)$ & $26(6)$ & $24(5)$ & $6(1)$ & 4.5 \\
\hline Fragmented & $32(9)$ & $22(4)$ & $7(1)$ & $30(8)$ & $20(3)$ & $7(1)$ & 1.5 \\
\hline \multicolumn{8}{|c|}{ Long-distance moves (\%) } \\
\hline Contiguous & $14(2)$ & $11(2)$ & $4(1)$ & $17(4)$ & $12(32)$ & $3(1)$ & 20 \\
\hline Fragmented & $19(2)$ & $15(2)$ & $2(1)$ & $27(3)$ & $22(2)$ & $5(2)$ & 0 \\
\hline \multicolumn{8}{|c|}{ Males that obtain a mate $(\%)$} \\
\hline Contiguous & $83(4)$ & $83(5)$ & $77(7)$ & $73(6)$ & $72(6)$ & $64(12)$ & 100 \\
\hline Fragmented & $72(4)$ & $69(5)$ & $61(6)$ & $55(7)$ & $50(5)$ & $38(11)$ & 13 \\
\hline
\end{tabular}

Notes: "Real" refers to observations and estimates made from data collected on Brown Treecreepers in the study area. Output parameters are described in detail in Methods: Model runs.

tance movements was higher in fragmented habitat than in contiguous habitat (Table 2). This difference was most apparent with the Random movement rule and the Constant dispersal mortality rate, and least apparent with an extreme matrix effect (Step 20); see Table 2.

Proportion of solitary males that obtain a mate.Solitary males in contiguous habitat were always more likely to obtain a mate than were solitary males in fragmented habitat (Table 2). Solitary males were more successful in obtaining mates when the Neighbor movement rule was in effect than when the rule was Random, especially in fragmented habitat, and with matrix effects (Table 2). Under the Random rule, 45$60 \%$ of solitary males in fragmented habitat died without obtaining a mate (Table 2). Runs using the Random movement rule and the most severe matrix effect (Step20) created the largest differences between populations in fragmented and contiguous habitat, and most closely matched field observations.

\section{DISCUSSION}

Our goal was to use a spatially explicit model to determine whether the effect of landscape structure on dispersal patterns might account for the decline of Brown Treecreepers in the New England Tablelands. The size of the simulated population over time was highly sensitive to the dispersal movement rule and to the dispersal mortality rule. Large differences in population size between fragmented and contiguous habitat were produced by differences in female dispersal success and recruitment, without any differences in birth and death rates. From these results, we draw several conclusions. First, the Random rule better matched field observations, suggesting that if dispersal behavior is sufficiently simple, then the distribution of woodland habitat can severely restrict the dispersal efficiency of
Brown Treecreepers. Second, the severe matrix effect most closely matched field observations, suggesting that Brown Treecreepers may experience high mortality in, or be unwilling to cross, nonwoodland habitat. Third, the relative influence of dispersal on population size was dependent on the spatial distribution of territories.

Movement rules.-The importance of territory aggregation in the model is ultimately linked to search strategies. Aggregation of territories allows dispersal success and recruitment under simple search rules, whereas dispersal success among non-aggregated territories requires complex search rules, such as Neighbor. Turner et al. (1993) reached similar conclusions in an analogous simulation of foraging ungulates in Yellowstone National Park, Wyoming, USA. They found that the arrangement of resources (clumped or random) mattered only when movement was limited.

Mortality rules.-In our simulations, matrix composition affected dispersal distances and success, leading to impacts on population persistence. Although long-distance dispersal events occurred at fairly low frequencies even in contiguous populations, matrix effects further decreased the frequency of long-distance movements and thus decreased female recruitment and, ultimately, population size. We only modeled two matrix effects, and more extreme effects are possible. For example, cleared land may be a complete barrier to Brown Treecreeper movements, rather than posing a great risk. As a barrier, cleared land may affect even short-distance movements. Cooper (2000) reported anecdotal evidence that nonforested habitat is a barrier to the movements of male Brown Treecreepers.

Dispersal success and population size.-Other simulations (e.g., McKelvey et al. 1993, Letcher et al. 1998) also found that dispersed territories resulted in 
lower population growth than did aggregated territories, due to more efficient searching by dispersers among aggregated territories. These studies illustrate the importance of dispersal behavior to population dynamics. However, dispersal behavior is not inevitably important to population persistence. South (1999) showed that errors in estimating dispersal success are not equivalent to errors in predicted population viability because dispersal success did not always have an effect on population persistence or patch occupancy. Specifically, South (1999) found that dispersal had a smaller effect on population persistence under model assumptions of saturation dispersal (any individuals in excess of patch carrying capacity dispersed) rather than presaturation dispersal (constant dispersal probability in each patch), and when simulations involved patches with high carrying capacities and were over short time periods. Pulliam et al. (1992) and Liu et al. (1995) found dispersal to be less important to population viability than other demographic factors, such as adult and juvenile survivorship.

In Brown Treecreeper simulations, $90 \%$ of movements were short distance $(<3.5 \mathrm{~km})$ and over $50 \%$ were $<1 \mathrm{~km}$. Given this, it is surprising that matrix effects influenced population behavior because the matrix is much more likely to affect long-distance than short-distance movements. Short-distance movements generally are within patches or between connected patches. It appears that long-distance movements between unconnected patches, although infrequent, may nevertheless be critical, perhaps due to demographic rescue (Stacey and Taper 1992). If habitat patches were less aggregated or smaller than in our study area, movements over longer distances would be more critical, creating a situation in which matrix elements could affect dispersal success even more strongly. If high environmental stochasticity were to cause local population extinctions, long-distance movements would be especially critical as well (Stacey and Taper 1992).

Territory arrangement.-This model, like most others, created isolation effects through a combination of movement rules and territory spacing. Therefore, the relevance of the results will depend not only on our knowledge of search patterns, but also on our knowledge of territory distribution, which has received little attention. In this model, territory spatial arrangement was not based on the actual coordinates of monitored territories; rather, territory locations were determined by habitat fragmentation patterns as well as by behaviors associated with territory formation (i.e., budding).

Brown Treecreepers territories are highly aggregated in contiguous habitat because of connections between patches and the presence of multiple territories within patches. Thus the simulations presented here may be a good reflection of real dynamics in contiguous habitat. However, Brown Treecreeper territories in our study area were not aggregated in fragmented habitat because patches were widely dispersed and most groups were the sole occupant in their patch. In order to match observed patterns, one would need to model fragmented patches as being sparsely populated. During simulations, the population in fragmented habitat never decreased to within-patch densities as low as those observed in the field. To account for observed densities in fragmented habitat, habitat quality in fragments must be either highly variable naturally or recently degraded, such that many areas in fragments are unsuitable woodlands. Hence, the fragmentation patterns that we mapped from aerial photographs may not be equivalent to the fragmentation patterns perceived by Brown Treecreepers. If so, then we may have underestimated habitat loss and fragmentation in the study area.

In summary, woodland fragmentation led to a nonaggregated distribution of territories in our study area. Evidently, a reduction in within-patch territory density for some other reason, such as habitat degradation, further decreased territory aggregation. Once territories are far apart, more long-distance dispersal movements are necessary. Population declines under these conditions may be explained by high mortality in nonwoodland habitat as well as low search efficiency when territories are not aggregated, which results in a low frequency of successful long-distance dispersal and insufficient recruitment. In order to verify the implications of our modeling, more research is needed to determine if movement patterns and dispersal behavior in the simulations are realistic.

Conservation implications.-Irrespective of habitat types, conservation efforts in fragmented systems usually focus on (1) reducing edge : area ratios either by increasing remnant size or optimizing remnant shapes (Temple and Cary 1988, Freemark et al. 1995, Stouffer and Bierregaard 1995, Graham and Blake 2001); or (2) improving the habitat within remnants by actions such as restoring natural disturbance regimes and preventing the removal of deadwood (Marzluff and Ewing 2001). Although this model dealt with a cooperatively breeding species, several conclusions emerge that are pertinent for any species under circumstances in which dispersal is the demographic process that limits population size. First, the matrix should be managed in such a way as to minimize dispersal risk, as others have emphasized (Harris and Scheck 1991, Franklin 1993, Marzluff and Ewing 2001). Second, conservation efforts should strive for habitat configurations that minimize dispersal search effort (i.e., aggregated habitat patches or territories).

Although advocates of movement corridors view the findings of reduced dispersal success in fragmented habitat as evidence of the need for corridors (Saunders and Hobbs 1991), we caution against drawing such a conclusion based on our findings. More research on movement patterns and dispersal decisions is needed before model findings are applied to conservation. Most research concerning search paths has been on invertebrates (see Wiens and Milne 1989, Turchin 
1998), but it is unclear how relevant or similar invertebrate movement rules are to those of vertebrates, particularly birds. Birds appear to be highly mobile under some circumstances, such as during migration, but even migrants appear to be constrained by some landscape features during short-distance movements (Desrochers and Hannon 1997, St. Clair et al. 1998). Without more information on how birds move through complex landscapes, the degree to which movement corridors can mitigate isolation effects will remain uncertain. For example, if a bird primarily follows habitat cues to guide dispersal movements, then corridors are likely to minimize both search effort and dispersal risk. On the other hand, if a bird primarily follows social cues (i.e., the presence of similar birds) to guide dispersal, then corridors designed for movement per se (i.e., scattered trees for Brown Treecreepers) might minimize dispersal risk, but not dispersal search effort. Reducing dispersal mortality is critical, but may be accomplished by aggregating habitat to reduce dispersal distances or by improving matrix quality. Aggregating habitat would also increase dispersal search efficiency and therefore may be the most promising conservation action, requiring fewer assumptions about decisions that guide dispersal.

Given the importance of the matrix and of habitat distribution, we would like to stress the importance of coordinating habitat restoration efforts among private landowners. Breeding habitats most often are on public lands or, if on private lands, are managed by incentive programs. However, as we move toward managing the landscape as a whole, it is critical to inform and coordinate conservation actions among private landowners. Without an effort to coordinate among neighboring landowners, it is difficult to include large-scale habitat configuration in management plans.

\section{ACKNOWLEDGMENTS}

The New South Wales Center for Land Management kindly granted access to aerial photographs of the study region. Financial support was provided by Sigma Xi, a Graduate Research and Development Program grant from VPI\&SU (Virginia Polytechnic Institute and State University), a National Science Foundation Dissertation Improvement Grant (DEB9801083), and the H. T. Bailey Foundation of VPI\&SU. We thank the field technicians, J. Auckland, S. Debus, J. Ford, R. Ryan, A. Stikkel, and F. Yench, for critical contributions to the project. Many thanks to the volunteers, S. Hamdorf, R. Sloan, L. Streeting, and S. Tremont, who helped with fieldwork. J. Cranford, C. Haas, B. Jones, and J. Webster helped to develop this research, and G. Passinelli, K. Schiegg, and three reviewers provided useful comments that improved this manuscript. Finally, we thank H. Ford for providing logistical support in carrying out the field research.

\section{Literature Cited}

Barrett, G. W. 1995. Woodland bird assemblages on the New England Tablelands, Northeastern New South Wales. Dissertation. University of New England, Armidale, New South Wales, Australia.

Barrett, G. W., H. A. Ford, and H. F. Recher. 1994. Conservation of woodland birds in a fragmented rural landscape. Pacific Conservation Biology 1:245-256.
Beissinger, S. R., and M. I. Westphal. 1998. On the use of demographic models in population viability in endangered species management. Journal of Wildlife Management 62: 821-841.

Caughley, G. 1994. Directions in conservation biology. Journal of Animal Ecology 63:215-244.

Cooper, C. B. 2000. Behavioral ecology and conservation of the Australian Brown Treecreeper (Climacteris picumnus). Dissertation. Virginia Polytechnic Institute and State University, Blacksburg, Virginia, USA.

Cooper, C. B., and J. R. Walters. 2002a. Experimental evidence of disrupted dispersal causing decline of an Australian passerine. Conservation Biology 16:471-478.

Cooper, C. B., and J. R. Walters. 2002b. Habitat and landscape effects on Brown Treecreeper distribution: independent effects of woodland loss and fragmentation at multiple scales. Biological Conservation 105:1-10.

Cooper, C. B., J. R. Walters, and H. A. Ford. In press. Effects of remnant size and connectivity on the response of Brown Treecreepers to habitat fragmentation. Emu.

Desrochers, A., and S. J. Hannon. 1997. Gap crossing decisions by forest songbirds during the post-fledging period. Conservation Biology 11:1204-1210.

Doak, D. F., P. C. Marino, and P. M. Kareiva. 1992. Spatial scale mediates the influence of habitat fragmentation on dispersal success: implications for conservation. Theoretical Population Biology 41:315-336.

Doerr, V. A. J., and E. D. Doerr. 2001. Brown Treecreeper. In P. J. Higgins, J. M. Peter, and W. K. Steele, editors. Handbook of Australian, New Zealand, and Antarctic Birds. Volume 5. Tyrant-flycatchers to Chats. Oxford University Press, Melbourne, Australia.

Donovan, T. M., P. W. Jones, E. M. Annand, and F. R. Thompson III. 1997. Variation in local-scale edge effects: mechanisms and landscape context. Ecology 78:2064-2075.

Dooley, J. L., Jr., and M. A. Bowers. 1996. Influence of patch size and microhabitat on the demography of two old-field rodents. Oikos 75:453-462.

Dooley, J. L., Jr., and M. A. Bowers. 1998. Demographic responses to habitat fragmentation: experimental tests at the landscape and patch scale. Ecology 79:969-980.

Fahrig, L. 1997. Relative effects of habitat loss and fragmentation on population extinction. Journal of Wildlife Management 61:603-610.

Fahrig, L. 1998. When does fragmentation of breeding habitat affect population survival? Ecological Modelling 105: 273-292.

Franklin, J. F. 1993. Preserving biodiversity: species, ecosystems, or landscapes. Ecological Applications 3:202205.

Freemark, K. E., J. B. Dunning, S. J. Hejl, and J. R. Probst. 1995. A landscape ecology perspective for research, conservation, and management. Pages 381-427 in T. E. Martin and D. M Finch, editors. Ecology and management of neotropical migratory birds. Oxford University Press, New York, New York, USA.

Gilbert, F., A. Gonzalez, and I. Evans-Freke. 1998. Corridors maintain species richness in the fragmented landscapes of a microecosystem. Proceedings of the Royal Society of London, B 265:577-582.

Graham, C. H., and J. G. Blake. 2001. Influence of patchand landscape-level factors on bird assemblages in a fragmented tropical landscape. Ecological Applications 11: 1709-1721.

Harris, L. D., and J. Scheck. 1991. From implications to applications, the dispersal corridor principle applied to conservation of biological diversity. Pages 189-220 in D. A. Saunders and R. J. Hobbs, editors. Nature conservation 2: the role of corridors. Surrey Beatty and Sons, Chipping Norton, New South Wales, Australia. 
Harrison, S., and E. Bruna. 1999. Habitat fragmentation and large-scale conservation: what do we know for sure? Ecography 22:225-232.

Keast, A. 1957. Variation and speciation in the genus Climacteris Temminck. Australian Journal of Zoology 5:474495.

Laurance, W. F., and R. Bierregaard. 1997. Tropical forest remnants: ecology, management and conservation. University of Chicago Press, Chicago, Illinois, USA.

Letcher, B. H., J. A. Priddy, J. R. Walters, and L. B. Crowder. 1998. An individual-based, spatially-explicit simulation model of the population dynamics of the endangered Redcockaded Woodpecker. Biological Conservation 86:1-14.

Liu, J., J. B. Dunning, and H. R. Pulliam. 1995. Potential effects of a forest management plan on Bachman's sparrow (Aimophila aestivalis): linking a spatially explicit model with GIS. Conservation Biology 9:62-75.

Marzluff, J. M., and K. Ewing. 2001. Restoration of fragmented landscapes for the conservation of birds: a general framework and specific recommendations for urbanizing landscapes. Restoration Ecology 9:280-292.

McGarigal, K., and W. C. McComb. 1995. Relationships between landscape structure and breeding birds in the Oregon coast range. Ecological Monographs 65:235-260.

McKelvey, K., B. R. Noon, and R. H. Lamberson. 1993. Conservation planning for species occupying fragmented landscapes: the case of the Northern Spotted Owl. Pages 424-450 in P. M. Kareiva, J. G. Kingsolver, and R. B. Huey, editors. Biotic interactions and global change. Sinauer, Sunderland, Massachusetts, USA.

Noske, R. A. 1982a. The private lives of treecreepers. Australian Natural History 20:419-424.

Noske, R. A. 1982b. Comparative behaviour and ecology of some Australian bark-foraging birds. Dissertation. University of New England, Armidale, New South Wales, Australia.

Pulliam, H. R., J. B. Dunning, Jr., and J. Liu. 1992. Population dynamics in a complex landscape: a case study. Ecological Applications 2:165-177.

Robinson, S. K., F. R. Thompson III, and T. M. Donovan. 1995. Regional forest fragmentation and the nesting success of migratory birds. Science 267:1987-1990.

Saunders, D. A., and R. J. Hobbs, editors. 1991. Nature conservation 2: the role of corridors. Surrey Beatty and Sons, Chipping Norton, New South Wales, Australia.

Schmiegelow, F. K. A., C. S. Machtans, and S. J. Hannon. 1997. Are boreal birds resilient to fragmentation? An experimental study of short-term community responses. Ecology 78:1914-1932.

Simberloff, D., J. A. Farr, J. Cox, and D. W. Mehlman. 1992.
Movement corridors: conservation bargains or poor investments? Conservation Biology 6:493-504.

South, A. 1999. Dispersal in spatially explicit population models. Conservation Biology 13:1039-1046.

St. Clair, C. C., M. Bélisle, A. Desrochers, and S. Hannon. 1998. Winter responses of forest birds to habitat corridors and gaps. Conservation Ecology 2(2):13. [Online, URL: $\langle$ http://www.consecol.org/vol2/iss 2/art13〉.]

Stacey, P. B., and M. Taper. 1992. Environmental variation and the persistence of small populations. Ecological Applications 2:18-29.

Stouffer, P. C., and R. O. Bierregaard, Jr. 1995. Use of Amazonian forest fragments by understory insectivorous birds. Ecology 76:2429-2445.

Temple, S. A., and J. R. Cary. 1988. Modeling dynamics of habitat-interior bird populations in fragmented landscapes. Conservation Biology 2:340-347.

Turchin, P. 1998. Quantitative analysis of movement: measuring and modeling population redistribution in animals and plants. Sinauer, Sunderland, Massachusetts, USA.

Turner, M. G., Y. Wu, W. H. Romme, and L. L. Wallace. 1993. A landscape simulation model of winter foraging by large ungulates. Ecological Modelling 69:163-184.

Trzcinski, M. K., L. Fahrig, and G. Merriam. 1999. Independent effects of forest cover and fragmentation on the distribution of forest breeding birds. Ecological Applications 9:586-593.

Villard, M., M. K. Trzcinski, and G. Merriam. 1999. Fragmentation effects on forest birds: relative influence of woodland cover and configuration on landscape occupancy. Conservation Biology 13:774-783.

Walters, J. R. 1998. The ecological basis of avian sensitivity to habitat fragmentation. Pages 181-192 in J. M. Marzluff and R. Sallabanks, editors. Avian conservation: research needs and effective implementation. Island Press, Washington, D.C., USA.

Walters, J. R., H. A. Ford, and C. B. Cooper. 1999. Variation in population structure and ecology of brown treecreepers between contiguous and fragmented woodland: a preliminary assessment. Biological Conservation 90:13-20.

Wiens, J. A., and B. T. Milne. 1989. Scaling of 'landscapes' in landscape ecology, or, landscape ecology from a beetle's perspective. Landscape Ecology 3:87-96.

Wiens, J. A., N. C. Stenseth, B. Van Horne, and R. A. Ims. 1993. Ecological mechanisms and landscape ecology. Oikos 66:369-380.

With, K. A. 1997. The application of neutral landscape models in conservation biology. Conservation Biology 11: 1069-1080.

Yates, C. J., and R. J. Hobbs. 1996. Woodland restoration in the Western Australian wheatbelt. A conceptual framework using a state and transition model. Restoration Ecology $\mathbf{5}$ : $28-35$. 